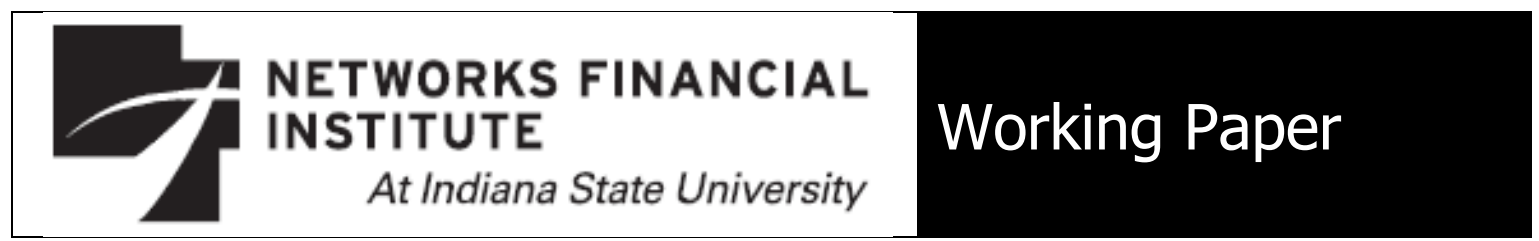

2011-WP-02

February 2011

\title{
Regulatory Restraints on Performance-Based Managerial Compensation, Bank Monitoring, and Aggregate Loan Quality David VanHoose
}

Abstract: This paper evaluates the effects of binding regulatory restraints on the rate of performance-based management compensation within a banking framework in which the primary function of bank management teams is to monitor loans in order to eliminate deadweight default losses. Available management teams are endowed with heterogeneous levels of monitoring efficiencies, and obtaining services from more efficient monitoring teams requires payment of higher rates of performance-based compensation. In equilibrium, a fraction of banks choose to employ management teams that monitor. With or without binding capital requirements, imposing binding restraints on the allowed rate of performance-based compensation results either in lower bank efficiency or in a reduced fraction of monitoring banks and, hence, lower aggregate loan quality.

About the Author: David VanHoose earned his Ph.D. at the University of North Carolina at Chapel Hill and is the Herman W. Lay Professor of Private Enterprise at the Hankamer School of Business, Baylor University. His work has appeared in Oxford Economic Papers, the Journal of International Money and Finance, and the European Journal of Political Economy. VanHoose served as a Visiting Economist at the Board of Governors of the Federal Reserve System in 1988 and as a Visiting Scholar at the Federal Reserve Bank of Kansas City in 1989. In 1991, he received the Iddo Sarnat Award for the outstanding article in the Journal of Banking and Finance, and in 1995 and 2000 he received the Atlantic Economic Journal's best article award. He is an editor of the Journal of Economics and Business and served on the editorial boards of Open Economies Review and the Atlantic Economic Journal. VanHoose is also the author of ECommerce Economics, co-author (with Roger Leroy Miller) of Macroeconomics: Theories, Policies, and International Applications and Money, Banking and Financial Markets, and co-author of International Monetary and Financial Economics and Global Economic Issues and Policies.

Keywords: Bank management compensation.

\section{JEL Classification: G28.}

The views expressed are those of the individual author and do not necessarily reflect official positions of Networks Financial Institute. Please address questions regarding content to David VanHoose at David_VanHoose@baylor.edu. Any errors or omissions are the responsibility of the author. NFI policy briefs and other publications are available on NFI's website (www.networksfinancialinstitute.org). Click "Thought Leadership" and then "Publications/Papers." 


\section{Regulatory Restraints on Performance-Based Managerial Compensation, Bank Monitoring, and Aggregate Loan Quality}

\section{Introduction}

Regulatory rules designed to limit bank management compensation arrangements have emerged in the aftermath of the Panic of 2008 and the associated government- and central bank-financed bailouts of financial institutions. These rules have included establishment of explicit pay ceilings for some institutions receiving "exceptional assistance" from the U.S. government, the publication and distribution of new supervisory guidelines for bank compensation policies by U.S. bank regulators, incorporation of reviews of pay programs into supervisory examinations, circulation of a proposal by the Federal Deposit Insurance Corporation to condition deposit insurance premiums on management compensation packages [see Adler (2010) and FDIC (2010)], and financial legislation signed into law in 2010 directing the Federal Reserve to establish formal regulatory standards for bank pay practices. As discussed by Hill (2009), similar regulations have advanced in other countries.

A number of critics of have expressed concerns that regulating bankers' pay amounts to an effort simply to "punish" bank managers instead of seeking to implement more meaningful reforms truly aimed at helping to prevent future crises. According to these and other critics, the regulation of bank management compensation at best is misguided and at worst counterproductive [see, for example, Mason (2009)].

Nevertheless, some observers suggest that shareholders can benefit from external curbs on management compensation [see, for instance, Grant and Grant (2008)], although most who argue in favor of rules constraining the scope of compensation packages at banks focus on policy-based justifications [see, for example, Macey and O'Hara (2003).

Among these is the argument that the unregulated utilization of performance-based pay for bank management teams could support efforts by equity holders to shift risk from 
themselves to other holders of bank debt-including depositors and hence government deposit insurers [see, for instance, Kose et al. (2000) and Raviv and Landskroner (2009)]. To the extent that deposit guarantees provide incentives for equity owners to deemphasize downside risks, this argument suggests, the use of performance-based management compensation contracts might induce managers to pursue these same artificially skewed interests of the equity owners. This concern that performance-based pay might contribute to the shifting of risks to taxpayers motivates most proposals to regulate the terms of bank management compensation arrangements [see VanHoose (2010) for a fuller discussion].

This paper seeks to demonstrate that there is nonetheless good reason to be concerned about the possibility for unintended distorting effects of regulatory restraints on performance-based pay. Banks hire managers to perform a variety of functions. One of the more important, highlighted in the work of Diamond $(1984,1991)$, is to address moral hazard risks via loan monitoring. The objective of this paper is to take seriously the idea that one reason that management teams at some banks receive higher rates of performance-based compensation is that they are better monitors than other management teams that banks might have hired. One key implication that emerges when attention is focused on the managerial loan-monitoring function is that placing binding restraints on rates of performance-based pay for bankers can cause banks to operate less efficiently while producing the same loan portfolios. Another is that placing sufficiently tight constraints on managerial compensation rates can generate a reduction in the aggregate quality of loans across the banking system.

The banking framework from which these conclusions are derived is intentionally stark. There is a perfectly competitive banking industry comprised of banks that are identically parameterized in all respects except the cost of monitoring loans. Monitoring loans eliminates a known per-dollar deadweight loss on a bank's loan revenues. The available bank management teams from whom banks may obtain monitoring expertise 
are endowed with heterogeneous monitoring efficiencies, and obtaining monitoring services from management teams that are able to monitor more efficiently requires paying them higher rates of performance-based compensation. Alternatively, banks may choose to pay a minimal rate of compensation to management teams with no monitoring capabilities - hence avoiding incurring any monitoring costs but consequently accepting the deadweight default loss on their loan revenues.

In the context of this basic banking model, it is possible to solve for an equilibrium share of banks that opt to pay sufficiently high rates of compensation to obtain the services of management teams with monitoring expertise. Once factors influencing the equilibrium split between banks offering adequate managerial compensation to monitor loans and banks that opt not to do so have been determined, it is straightforward to derive predictions about effects of imposing binding constraints on rates of performance-based bank management compensation. These effects can be summarized briefly as follows.

Compensation rules establishing a constraint on the rate of management compensation that is below the rate that some monitoring banks pay to obtain the most efficient monitoring teams can result in one of two possible outcomes. The first outcome arises if management teams only offer "take-it-or-leave-it" contracts, meaning that they will only monitor loans at high compensation rate corresponding to greater monitoring efficiency. In this case, some banks that otherwise would have paid high rates of compensation will lose these management teams' services and opt to become nonmonitors, meaning that aggregate loan quality will decline. The other possible outcome applies to banks that are able to successfully bargain to pay the most efficient management teams lower compensation rates that satisfy the regulatory restraint in return for less efficient monitoring. In this case, aggregate loan quality remains unchanged, but bank efficiency decreases, and the market values of the most efficient monitoring banks affected by the regulation decline. If a regulatory binding restraint on the rate of 
performance-based compensation is tightened to a level below the rate of compensation paid by the bank exactly on the extensive margin between monitoring and not monitoring, then these possible outcomes can apply to all monitoring banks. Thus the regulatory restraint results either in some reduction in the efficiency of monitoring banks or a decrease in aggregate loan quality. These results follow whether or not banks are also subject to capital requirements limiting total lending in relation to equity capital.

The next section describes the banking framework utilized in the paper and explains its implications for the determination of the equilibrium share of banks that pay sufficiently high rates of management compensation to obtain management teams that monitor loans and eliminate default losses to loan revenues. Section 3 evaluates the model's implications for the effects of binding constraints on rates of performance-based compensation, which yields the key predictions summarized in the previous paragraph. Section 4 evaluates an alternative setting in which all banks are also bound by capital regulation that limits their lending in relation to their equity capital. The same basic qualitative conclusions follow, although the analysis indicates that the quantitative magnitudes of the effects of binding regulatory restraints on bank management compensation would differ in a capital-regulated banking system. Section 5 concludes.

\section{Performance-Based Compensation for Loan Monitoring Expertise}

Consider the following two-period banking model, which is based on banking models utilized by Kopecky and VanHoose (2006 and 2010). There are numerous banks that are the same in every respect except (1) whether they choose to monitor loans to eliminate an identical deadweight, per-dollar default loss known by all banks to arise when loans are not monitored, (2) the rates of performance-based compensation paid to management teams, and (3) the levels of monitoring efficiency associated with selected

management teams - all points discussed in more detail below. In period 0, a given bank $j$ offers equity shares to the public, and these shares generate an aggregate equity cash 
flow, $E_{j, B K}$. Under the assumption of a perfectly competitive capital market, competition among potential equity owners will induce an equity cash investment in the bank (the book value of equity) that is equal to the bank's market value of equity; that is, Tobin's $Q$ takes on a value of unity. Bankruptcy is assumed not to occur, and complete certainty is assumed throughout. Hence, the deposit rate, $r_{D}$, that the bank must pay on an exogenous amount of one-period insured deposits, $D$, is known in period 0 . The scale of the bank is equal to the sum of $D$ and $E_{j, B K}$, and the bank converts these liabilities into an asset portfolio consisting of one-period government securities, $G_{j}$, paying a risk-free interest rate $r_{G}$, non-interest-bearing required reserves, $R_{j}$, and one-period loans $L_{j}$, at the loan rate, $r_{L}$. In period 1 , the bank receives gross revenues from loan and securities, obtains required reserves from the monetary authority, makes gross payments to depositors, provides managers with performance-based compensation, and distributes net proceeds to its equity owners. In the complete-certainty setting considered, gross revenues and expenses in period 1 are foreseen and discounted back to date 0 , yielding the market value of the bank, $E_{j, 0}$. Thus,

$$
E_{j, 0}=\frac{\hat{\pi}_{j, 1}}{1+\beta},
$$

where $\hat{\pi}_{j, 1}$ is the net cash flow accruing to equity owners during period 1 (defined below) and $\beta$ is the discount rate. The bank's maximization of (1) at date 0 is subject to alternative sets of the following constraints, depending on whether binding capital requirements are present:

Balance sheet $(\mathrm{t}=0): \quad \quad R_{j}+G_{j}+L_{j}=D+E_{j},_{B K}$ :

Reserve requirement: $\quad R_{j} \geq \rho D$ :

Capital requirement: $\quad E_{j, B K} \geq \theta L_{j}$ : 
where $\rho$ is the effective required reserve ratio, and $\theta$ is the capital requirement ratio. Equation (2) is the bank's balance sheet constraint, (3) is the reserve-requirement constraint, and (4) is a risk-based capital requirement on loans that is defined in relation to the amount of book equity. Any imposition of capital requirements is assumed to be recognized ex ante by the bank.

The total net cash flow to equity owners at date $1, \tilde{\pi}_{j, 1}$, depends on whether a bank chooses to monitor. If the bank is among the group of monitoring $(m)$ banks, then its total net cash flow is

$$
\tilde{\pi}_{j, 1}^{M}=\left(1+r_{L}\right) L_{j}+\left(1+r_{G}\right) G_{j}-\left(1+r_{D}\right) D+R_{j}-\left(\frac{f+c_{j}}{2}\right) L_{j}^{2},
$$

where the subscript " 1 " denotes that this cash flow applies to period 1. For banks that choose to be non-monitoring $(\mathrm{nm})$ institutions, the total net cash flow is

$$
\tilde{\pi}_{j, 1}^{N M}=(1-\delta)\left(1+r_{L}\right) L_{j}+\left(1+r_{G}\right) G_{j}-\left(1+r_{D}\right) D+R_{j}-\frac{f}{2} L_{j}^{2}
$$

In (5a) and (5b), the parameter $f$ determines the magnitude of quadratic resource expenses entailed in lending that are unrelated to monitoring. A positive value of $f$ ensures an upward-sloping marginal resource cost of lending, which by assumption is unrelated to other sources of marginal costs. Resource costs of deposits could also be included without altering the results since, under the assumption of exogenous deposits, such costs would be fixed during the time horizon considered. As shown by Elyasiani et al. (1995), the presumed absence of resource costs for securities is consistent with the assumption of portfolio separation, so that banks' asset and liability decisions are independent.

The expression in (5b) indicates that if the bank opts not to monitor its loans, it escapes incurring a monitoring cost but must then experience the $\delta$ loss on its loan revenues. In contrast, (5a) indicates that if the bank incurs an additional quadratic 
monitoring cost with a magnitude determined by the value of the parameter $c_{j}$, it can eliminate a known, per-dollar deadweight default loss $\delta$. We assume that the minimum feasible magnitude of the parameter $c_{j}$ is directly related to the amount of performancebased compensation that the bank pays to managers in period 0 . This compensation is equal to $e_{j} \pi_{j, 1}$, where $e_{j}$ is the fraction of the period 1 net cash flow paid to managers. Thus, the actual net cash flow accruing to equity holders during period 1 , after subtracting the performance-based compensation paid to managers, is equal to $\hat{\pi}_{j, 1}=$ $\left(1-e_{j}\right) \tilde{\pi}_{j, 1}$

Banks can select from among two sets of available managerial teams distributed over the unit interval. One set of teams, which are available at any point along the unit interval, possess no monitoring abilities and can be hired at a minimal rate of management compensation denoted $e^{N M}$. The second set of management teams, which also are distributed over the unit interval, are endowed with heterogenous abilities to monitor loans and thereby remove the deadweight per-dollar default loss. Providing performance-based pay to managers from among this set yields monitoring services sufficient to yield a corresponding lowest-feasible magnitude of $c_{j}$ that the hired management team can provide at the corresponding rate of performance-based compensation, $e_{j}$, applied to the bank's gross cash flow, $\tilde{\pi}_{j, 1}$.

The determination of a monitoring bank's position along the unit interval hinges on its choice from among a fixed range of individually unique $\left\{e_{j}, c_{j}\right\}$ combinations available along the interval. Let's suppose that if bank $j=1$ desires to hire a management team that will monitor its loans, it pays the lowest feasible rate of managerial compensation, $e_{1} \equiv \underline{e}>e^{N M}$, which enables it to obtain a management team willing and able to do so but at the highest value of $c_{j}$. In contrast, suppose that bank $j=0$ wishes to hire the management team capable of monitoring loans at the lowest feasible cost parameter value, assumed to be $c_{0}=0$, which requires this bank to pay the highest 
available rate of compensation, $e_{0}=\bar{e}>\underline{e}$. There are many ways in which one might imagine distributing the range of $\left\{e_{j}, c_{j}\right\}$ combinations over the unit interval. For simplicity, the assumed distribution of $c_{j}$ endowments is assumed to be given by $c_{j}=\left(\frac{j}{1-j}\right) c$, where $c$ is a constant and that the corresponding distribution of $e_{j}$ payments required to elicit this range of minimum-feasible monitoring-cost parameters is the linear combination of $\underline{e}$ and $\bar{e}$ given by $e_{j}=j \underline{e}+(1-j) \bar{e}$. An appealing feature of this specific structure of $\left\{e_{j}, c_{j}\right\}$ combinations, which is depicted in Figure 1, is that it is consistent with diminishing marginal gains from performance-based compensation: because $c_{j}$ is nonlinearly related to $j$ while $e_{j}$ is linearly related, progressively higher rates of performance-based compensation yield diminishing feasible improvements in monitoring efficiency. 
Figure 1: Monitoring Performance-Based Compensation Rates and Monitoring Costs

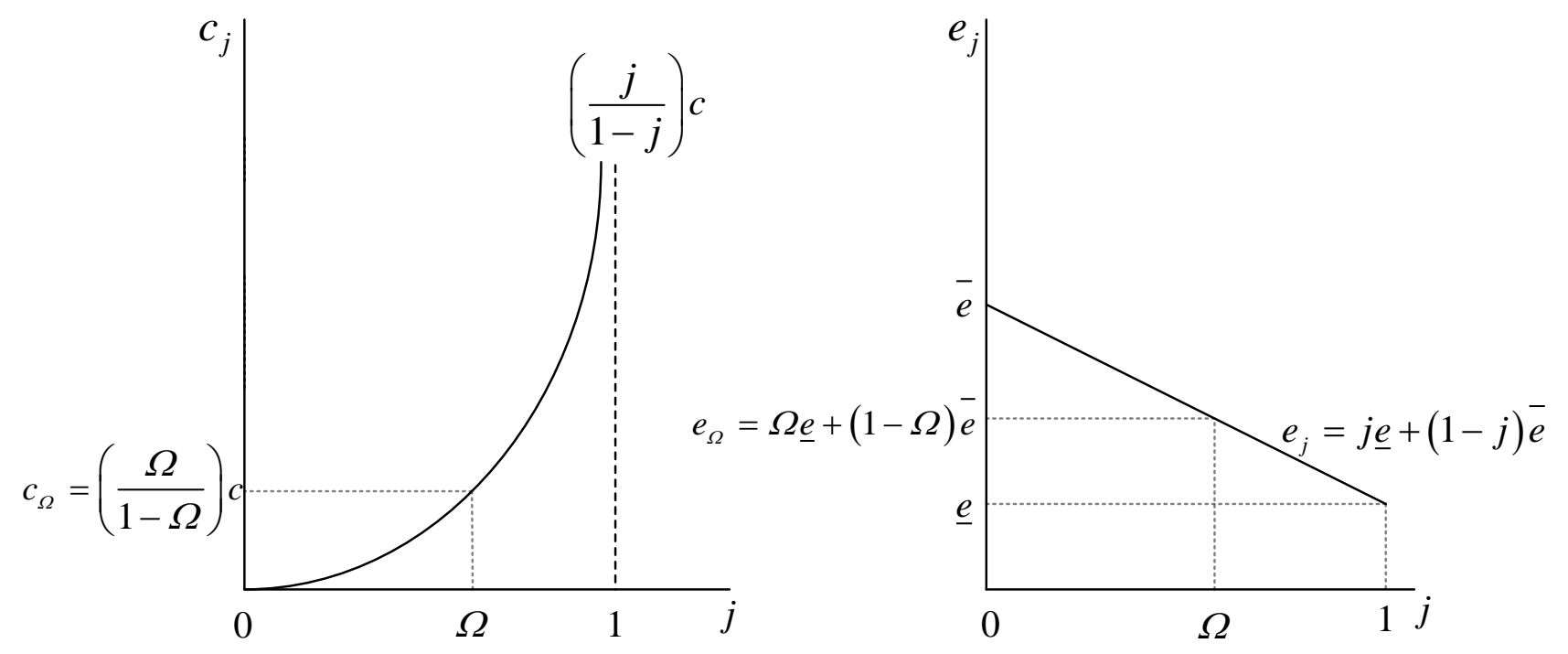


If there is neither a regulatory constraint on bank managerial compensation nor a regulatory capital requirement, an individual bank $j$ maximizes the market value of its equity, $E_{j, 0}=\frac{\hat{\pi}_{j, 1}}{1+\beta}$, as both a potential monitor and non-monitor of loans and then chooses the monitoring strategy that gives the highest equity value. In each case, the maximization problem for the otherwise unregulated bank is subject to (2) and (3). For a bank that monitors its loans, $\hat{\pi}_{1}$ is given by $\hat{\pi}_{1}^{m}$ in (5a), while for a non-monitoring bank, $\hat{\pi}_{1}$ is given by $\hat{\pi}_{1}^{n m}$ in (5b). Figure 1 depicts one conceivable situation, in which a fraction of banks $\Omega$ hires from among available loan-monitoring management teams at a performance-based compensation rate $e_{j}>e_{\Omega}$ and by doing so attains an equity value at least as high as the fraction (1- $\Omega$ ) of banks that hire from the alternative set of non-loanmonitoring management teams at the minimal compensation rate $e_{j}=e^{N M}$. Thus, in this situation, banks to the left of position $\Omega$ along the unit interval opt to hire management teams that would monitor their loans and eliminate the deadweight, per-dollar default loss to loan revenues, while banks to the right of position $\Omega$ do not.

The first step in solving for the value of $\Omega$ is to determine the loan quantities that maximize the cash flows of monitoring and non-monitoring banks. These are, respectively,

$$
L_{j}^{M^{*}}=\frac{r_{L}-r_{G}}{f+c_{j}},
$$

and

$$
L^{N M^{*}}=\frac{(1-\delta)\left(1+r_{L}\right)-\left(1+r_{G}\right)}{f}
$$

where $L^{N M^{*}}$ is identical across non-monitoring banks. Using (6a) in the balance-sheet constraint (2) to eliminate $G_{j}$, substituting into (5a), and solving the valuation equation (1) yields the following maximized market value of equity for a monitoring bank, $E_{j, 0}^{M}$, conditional on a fixed amount of book equity, $E_{B K}$, 


$$
E_{j, 0}^{M}=\frac{\left(1-e_{j}^{M}\right)\left\{\left(1+r_{G}\right) E_{B K}+\left[r_{G}(1-\rho)-r_{D}\right] D+\frac{\left(r_{L}-r_{G}\right)^{2}}{2(f+c)}\right\}}{1+\beta},
$$

where $e_{j}^{M}$ is the performance-based management compensation rate paid to managers from among the set of management teams endowed with loan-monitoring capabilities.

Obtaining the equity analogue for a non-monitoring bank, $E_{0}^{N M}$, requires substituting (6b) into (2) to eliminate $G_{j}$, substituting into (5b) and solving (1) for this case:

$$
E_{0}^{N M}=\frac{\left(1-e^{N M}\right)\left\{\left(1+r_{G}\right) E_{B K}+\left[r_{G}(1-\rho)-r_{D}\right] D+\frac{\left[(1-\delta)\left(1+r_{L}\right)-\left(1+r_{G}\right)\right]^{2}}{2 f}\right\}}{1+\beta} .
$$

The long-run capital-market equilibrium condition requires that Tobin's $Q$ equals unity, so that cash in the form of equity is invested in the banking system to the point at which the book and market values of equity are equal:

$$
E_{j, 0}=E_{j, B K}
$$

Taking into account the maintained assumption that deposits are riskless and assuming that the deposit market is perfectly competitive implies that the deposit rate must satisfy $r_{D}=(1-\rho) r_{G}$; that is, it must equal the reserve-requirement-adjusted security rate. Using this fact and substituting (7a) and (7b) into (8) yields the model's equilibrium long-run market equity values for monitoring $\left(E_{j, 0}^{M^{*}}\right)$ and non-monitoring $\left(E_{j, 0}^{N M^{*}}\right)$ banks:

$$
E_{j, 0}^{M^{*}}=\frac{\left(1-e_{j}^{M}\right)\left(r_{L}-r_{G}\right)^{2}}{2\left(f+c_{j}\right)\left[(1+\beta)-\left(1-e_{j}^{M}\right)\left(1+r_{G}\right)\right]},
$$

and

$$
E_{0}^{N M^{*}}=\frac{\left(1-e^{N M}\right)\left[(1-\delta)\left(1+r_{L}\right)-\left(1+r_{G}\right)\right]^{2}}{2 f\left[(1+\beta)-\left(1-e^{N M}\right)\left(1+r_{G}\right)\right]} .
$$


Equations (9a) and (9b) imply that the market value of equity at all banks is increasing in factors that raise net cash flow available to equity owners at date 1 , such as a higher market loan rate or a lower value of $f$ that would yield reduced loan resource costs. For a bank that opts to employ a loan-monitoring management team, deadweight loan default losses are eliminated, but equity owners receive a smaller cash flow net of incurred monitoring costs and of payments of performance-based managerial compensation rates to loan-monitoring managers. For a bank that chooses not to monitor, net loan revenues are reduced by the per-dollar deadweight default loss $\delta$, yet at the same time the equity owner's overall net cash flow is higher because the bank neither incurs monitoring costs nor pays a higher management compensation rate.

Comparing (9a) to (9b) indicates that $E_{j, 0}^{M^{*}}>E_{0}^{N M^{*}}$, so that a bank $j$ will choose to provide a sufficiently high rate of performance-based compensation to hire a management team capable of monitoring loans, under the following condition:

$$
j<\Omega \equiv \frac{\left(A_{\Omega}-B_{\Omega}\right) f}{B_{\Omega} c+\left(A_{\Omega}-B_{\Omega}\right) f},
$$

where $\Omega$ thereby defines the equilibrium share of banks that monitor their loans and where $A_{\Omega} \equiv\left(1-e^{N M}\right)\left[(1-\delta)\left(1+r_{L}\right)-\left(1+r_{G}\right)\right]^{2}\left[(1+\beta)-\left(1-e_{\Omega}^{M}\right)\left(1+r_{G}\right)\right]$, $B_{\Omega} \equiv\left(1-e_{\Omega}^{M}\right)\left(r_{L}-r_{G}\right)^{2}\left[(1+\beta)-\left(1-e^{N M}\right)\left(1+r_{G}\right)\right]$, and $e_{\Omega}^{M} \equiv \Omega \underline{e}+(1-\Omega) \bar{e}$. Note that $A_{\Omega}-B_{\Omega}>0$ for wide ranges of parameter values, particularly if $e_{\Omega}^{M}$ is sufficiently large relative to $e^{N M}$ — so that obtaining management teams adept at loan monitoring requires sufficiently high performance-based pay in relation to the pay required for managers unequipped to monitor loans. These ranges of parameter values yield $0<\Omega<1$ as the typical outcome. Naturally, if the value of $\delta$ rises-so that banks experience greater exposure to deadweight per-dollar default losses, or the value $c$ declines, so that all loanmonitoring management teams exogenously experience improved efficiency in engaging 
in monitoring - then the value of $\Omega$ rises; either parameter change induces more banks to monitor their loans.

\section{The Impact of Restraining Performance-Based Management Compensation}

What happens if regulators set an effective constraint on the rate of performancebased compensation? The answer to this question depends on the degree to which the constraint limits banks' options. Figure 2 evaluates a situation in which a regulatory limitation on the management performance-compensation rate, denoted $e^{*}$, is set beneath $\bar{e}$ but exceeds $e_{\Omega}^{M}$. In this situation, bank management teams requiring performancecompensation rates between $e^{*}$ and $\bar{e}$ to provide minimum-feasible-cost monitoring services will withhold them. If management teams capable of providing loan-monitoring cost parameters in the range from 0 to $c_{\Omega}$ are willing to offer only take-it-or-leave-it deals, then the share of banks $\Gamma^{*}$ will be unable to hire those teams of managers, and the share of banks engaging in loan monitoring will drop from $\Omega$ to $\Omega-\Gamma^{*}$. In this case, aggregate loan quality in the banking system declines as a result of the regulatory restraint on performance-based management compensation. 
Figure 2: A Binding Constraint on the Rate of Performance-Based Compensation between $e_{\Omega}$ and $\bar{e}$
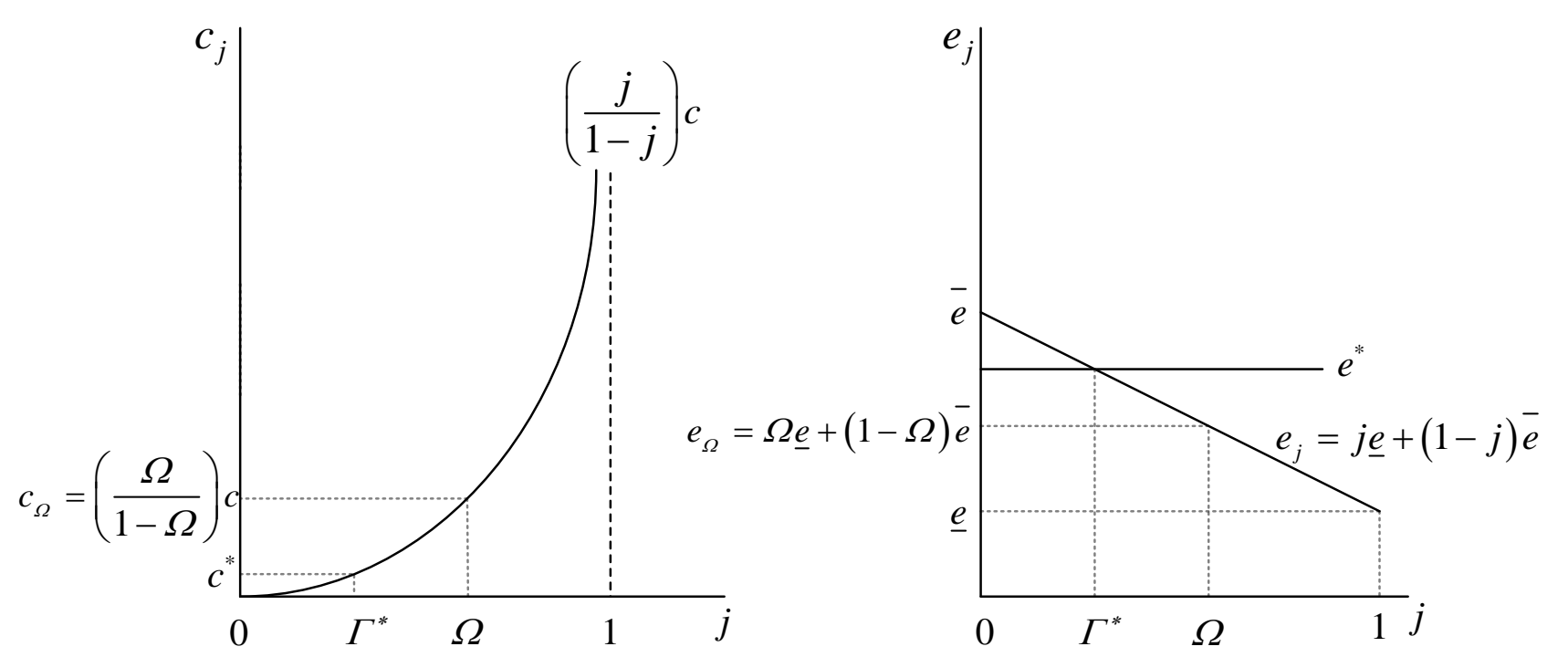
Of course, banks only require a loan-monitoring cost parameter smaller than $c_{\Omega}$ at a performance-based compensation rate lower than $e_{\Omega}^{M}$ to yield a higher market value of equity under monitoring than in the absence of monitoring. Thus, if they can bargain with the loan-monitoring management teams capable of providing loan-monitoring services at parameter values below $c^{*}$ to accept instead a compensation rate $e^{*}$ to provide monitoring services less efficiently at costs consistent the cost parameter $c^{*}$, then the aggregate share of banks that monitor loans can remain at $\Omega$. Consequently, the banking system would produce the same quantity and quality of loans but would do so less efficiently. In addition, the market value of equity at affected banks likely would decline, since monitoring efficiency, which varies nonlinearly, would be considerably lower, while rates of management compensation, which varies linearly, would be only moderately lower.

What if a restriction on performance-based compensation to management teams is tightened to a level lower than $e_{\Omega}^{M}$, such as $e^{* *}$ in Figure 3? In such a situation, no monitoring bank is allowed to pay a compensation rate sufficient to obtain a management team that is capable of generating a loan-monitoring cost parameter below $c^{* *}$, which exceeds the minimum parameter value of $c_{\Omega}$ required to induce the share of banks $\Omega$ to opt to monitor loans. Consequently, it is no longer feasible to attain a market value of equity under monitoring that at least matches the level without monitoring. Thus, under this more severe constraint on the management-compensation rate, every bank that previously engaged in monitoring either suffers reduced efficiency (if it can induce management teams to provide less efficient monitoring services at the lower rate of compensation) or opts to halt its monitoring. Either efficiency levels decline or the aggregate quality of bank loans drops at all banks that had been monitoring prior to the tightening of the compensation restraint. 
Figure 3: A Binding Constraint on the Rate of Performance-Based Compensation between $\underline{e}$ and $e_{\Omega}$

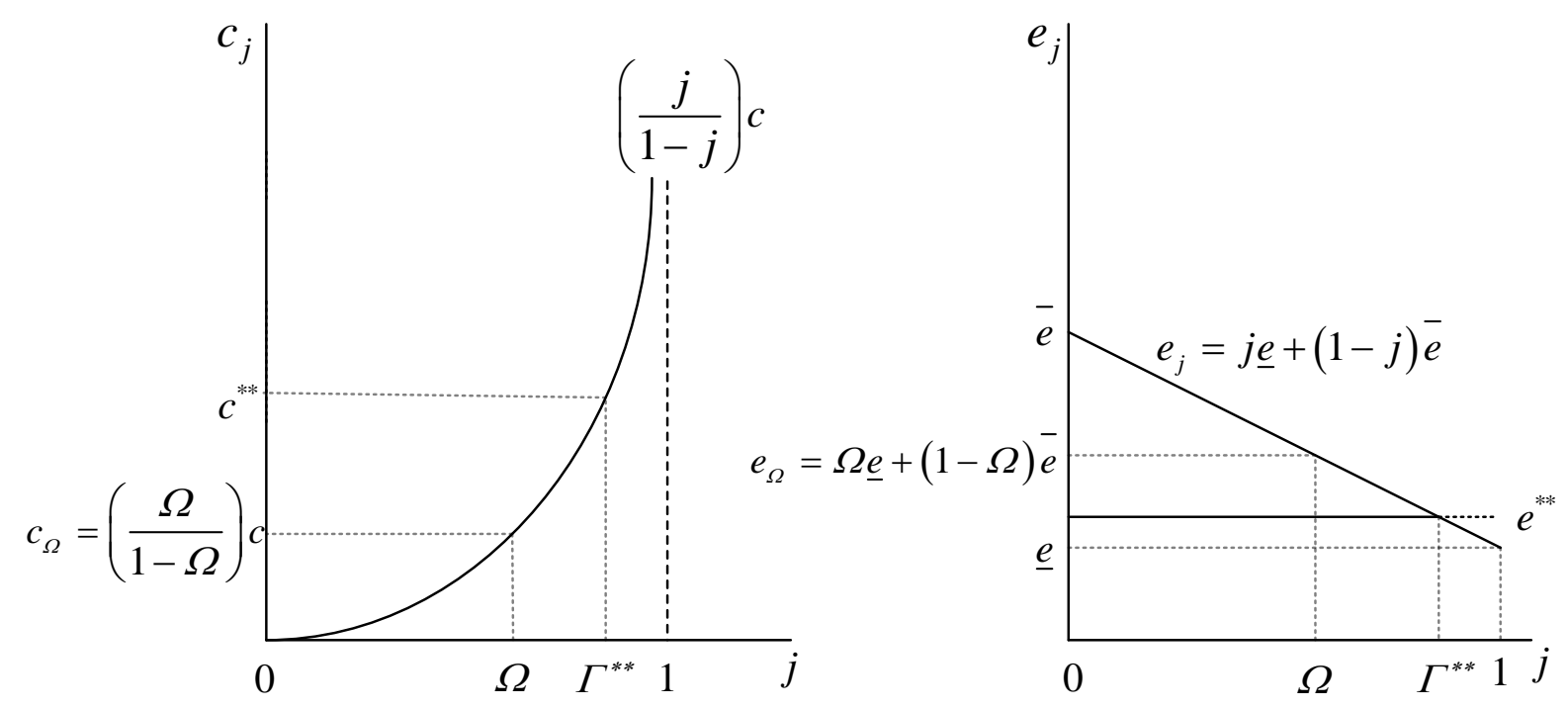


It is important to recognize a caveat regarding the above conclusions. Whenever some banks switch from monitoring loans in favor of not doing so, this must affect the total market supply of loans, which in turn will - as long as loan demand is not perfectly inelastic - generate a change in the market loan rate. The values of $A_{\Omega}$ and $B_{\Omega}$ depend on the market loan rate, so in fact the level of $\Omega$ must adjust somewhat in response to the imposition of regulatory constraints such as $e^{*}$ and $e^{* *}$ depicted in Figures 2 and 3. In principle, this second-order effect could be taken into account by proposing a specific form for the loan demand curve and simulating solutions for $\Omega$ (for details regarding such an approach, see Kopecky and VanHoose, 2006). In most cases, however, the qualitative implications of the comparative-statics effects illustrated in the two figures is unlikely to be affected.

\section{Binding Constraints on Performance-Based Compensation and Aggregate Loan Quality under Capital Requirements}

Of course, the recent decision to regulate bank management compensation has also been accompanied by movement toward establishment of a Basel III system of capital regulation employing higher required capital ratios relating bank loans to equity capital. From (4), when risk-based capital regulation is binding, a bank $j$ 's volume of loans is, whether or not the bank engages in monitoring, equal to (with a tilde denoting capital-constrained values of all relevant variables):

$$
\tilde{L}_{j}=\frac{\tilde{E}_{j, B K}}{\theta}
$$

Using the same procedure as in Section 2, expressions for market values of equity at monitoring and non-monitoring banks can be derived by computing the market value of equity conditional on a given amount of book equity, $\tilde{E}_{j, B K}$, assuming a competitive 
deposit market, and then equating the market and book values of equity. This gives the following expressions for the period 0 market equity values:

$$
\tilde{E}_{0}^{M^{*}}=\left(\frac{2 \theta^{2}}{\left(1-e_{j}^{M}\right)\left(f+c_{j}\right)}\right)\left[\frac{\left(1-e_{j}^{M}\right)\left(\tilde{r}_{L}-r_{G}\right)}{\theta}-\left(\beta-r_{G}\right)\right]
$$

and

$$
\tilde{E}_{0}^{N M^{*}}=\left(\frac{2 \theta^{2}}{\left(1-e^{N M}\right) f}\right)\left\{\frac{\left(1-e^{N M}\right)\left[(1-\delta)\left(1+\tilde{r}_{L}\right)-\left(1+r_{G}\right)\right]}{\theta}-\left(\beta-r_{G}\right)\right\} .
$$

Thus, under capital regulation, the condition under which a bank $j$ will choose to provide a sufficiently high rate of performance-based compensation to hire a management team capable of monitoring loans is given by

$$
j<\tilde{\Omega} \equiv \frac{\left(\tilde{A}_{\Omega}-\tilde{B}_{\Omega}\right) f}{\tilde{B}_{\Omega} c+\left(\tilde{A}_{\Omega}-\tilde{B}_{\Omega}\right) f},
$$

where $\tilde{\Omega}$ is the implied equilibrium share of banks at which management teams monitor loans, $\tilde{A}_{\Omega} \equiv\left(1-e_{\tilde{\Omega}}^{M}\right)\left\{\left(1-e^{N M}\right)\left[(1-\delta)\left(1+\tilde{r}_{L}\right)-\left(1+r_{G}\right)\right]-\theta\left(\beta-r_{G}\right)\right\}$, $B_{\tilde{\Omega}} \equiv\left(1-e^{N M}\right)\left[\left(1-e_{\tilde{\Omega}}^{M}\right)\left(\tilde{r}_{L}-r_{G}\right)-\theta\left(\beta-r_{G}\right)\right], \tilde{r}_{L}$ is the market loan rate under capital regulation (which is larger than the unregulated loan rate since binding capital regulation pushes down aggregate loan supply), $e_{\tilde{\Omega}}^{M} \equiv \tilde{\Omega} \underline{e}+(1-\tilde{\Omega}) \bar{e}$, and $A_{\tilde{\Omega}}-B_{\tilde{\Omega}}>0$ for wide ranges of parameter values, particularly if $e_{\Omega}^{M}$ is sufficiently large relative to $e^{N M}$. For these ranges of parameter values, $0<\tilde{\Omega}<1$ emerges as the typical outcome, and again if 
$\delta$ rises in value or c falls in value, $\tilde{\Omega}$ increases.

The $\tilde{\Omega}$ share of banks that monitor their loans under capital regulation is difficult to compare analytically with the unregulated monitoring share, $\Omega$, computed in section 2 . Kopecky and VanHoose (2006) conduct calibrated simulations of a similar model indicating that $\tilde{\Omega}<\Omega$ - that is, a smaller share of capital-constrained banks opting to monitor their loans - may be the most plausible outcome from an empirical standpoint. As Kopecky and VanHoose emphasize, from this standpoint, imposing capital regulation that is binding on all banks has an ambiguous effect on aggregate loan quality: on one hand there are fewer loans exposed to default losses, but on the other hand fewer banks monitor their loans in an effort to eliminate such losses.

In the context of the present analysis, the issue of primary interest is evaluating the effect of restraining the rate of performance-based management compensation. The qualitative effects of binding constraints on the rate of managerial compensation are analogous to those depicted in Figures 2 and 3, but with $\tilde{\Omega}$ replacing $\Omega$. Hence, the model's analytical predictions regarding effects of binding constraints on performancebased compensation rates under binding capital requirements parallel the predictions forthcoming from the unregulated banking framework.

Note, however, that for the assumed ranges of parameter values, $\frac{\partial \tilde{\Omega}}{\partial \theta}>0$; thus, increasing the risk-based capital requirement for an already capital-constrained banking system induces more banks to monitor. Once banks are already capital-constrained, an additional forced reduction in lending in response to a tighter capital requirement pushes down marginal monitoring costs. This, ceteris paribus, boosts the market value for a bank if it opts to monitor, so more banks near the extensive margin regarding the monitoring decision choose to hire management teams possessing monitoring expertise. Consequently, if a regulatory constraint on management compensation sufficiently binds a banking system subject to capital regulation to generate a reduction in aggregate loan 
quality, tightening capital standards can help to push loan quality back up. Coupling regulation of bank management compensation with toughened Basel III-type capital standards in this model banking system conceivably could, in this particular situation, maintain aggregate loan quality at previous levels. Of course, this is not the standard argument for a coupling these regulatory policies in the real world.

What if capital requirements only partially bind the banking system? Kopecky and VanHoose (2006) provide an example of how to analyze this case. Evaluating this case would require aggregating bank loan supplies, combining them with a loan demand function, and considering a capital requirement that only binds a fraction of the model banks. Obtaining potentially useful implications in the context of such an expanded analytical framework would require conducting calibrated simulations. The results that Kopecky and VanHoose obtained in their efforts along these lines indicate that outcomes in a partially capital-constrained banking system lie between the two extremes of no capital regulation and fully binding capital requirements, with essential qualitative implications analogous to those to the case of a fully capital-constrained banking system. This conclusion suggests that the effects of imposing regulatory restraints on allowed rates of performance-based management compensation would also apply to a partially capital-constrained banking system.

\section{Conclusion}

This paper has sought to derive predictions about effects of placing binding restraints on rates of compensation that banks are allowed to pay when management teams differ in relative rates of compensation required to elicit varying efficiencies in providing loan-monitoring services. The paper's objective, therefore, has been to take seriously the view that a fundamental function of bank managers is to monitor loans with an aim to eliminate default losses on loan revenues. Toward this end, it has developed and analyzed a model of a perfectly competitive banking system in which banks can 
contemplate employing heterogenous management teams. In the model, these management teams include both teams that do not monitor loans and hence provide their services at the lowest feasible rate of performance compensation and teams that offer progressively greater degrees of loan-monitoring efficiency in return for correspondingly higher rates of performance-based compensation. This framework yields an equilibrium share of banks willing to pay rates of compensation sufficiently high to obtain services of management teams that monitor loans and thereby eliminate default losses. Analysis of this model with and without binding capital requirements on banks indicates that imposing a binding constraint on the allowed rate of management compensation would at best leave aggregate loan quality unaffected but even then would reduce the efficiency of the constrained portion of the banking system. A sufficiently tightened regulatory restraint on the allowed rate of management compensation would either cause efficiency levels to decline or induce a switch to non-monitoring status and lower loan quality at all previously monitoring banks.

Of course, these conclusions have been obtained within a stark framework in which paying bank management teams a higher rate of performance based compensation has no effects other than to generate unambiguously greater monitoring efficiency. As noted in the introduction, bank management compensation regulations are predicated on the argument that the provision of government deposit guarantees creates incentives for equity holders to try to shift risks of losses to government guarantors by inducing managers to take into account only equity owners' interests. The model analyzed in this paper is much too limited to take this risk-shifting issue into account. Nevertheless, the conclusions obtained from the model suggest that in a framework in which both monitoring-efficiency and risk-shifting effects of performance-based pay for bank managers could be contemplated simultaneously, the implications of imposing binding constraints on performance-based compensation theoretically would be ambiguous. Such regulatory restraints could indeed reduce risk-shifting incentives, yet at the same time the 
analysis above indicates that such restraints must also contribute to reduced efficiency of bank operations and potentially to lower quality of bank loan portfolios. It is not clear whether regulators currently charged with developing rules governing bank management compensation recognize fully the nature of this trade-off — or others that undoubtedly exist with respect to other roles of bank managers, such as performing screening, portfolio management, and other fundamental banking functions. Evaluating the nature of such trade-offs constitutes an appropriate direction for research on the topic of regulation of bank management compensation. 


\section{REFERENCES}

Adler, Joe, 2010, FDIC board split on exec pay plan, American Banker, January 13.

Diamond, Douglas, 1991. Monitoring and regulation: The choice between bank loans and directly placed debt. Journal of Political Economy 99, 689-721.

Diamond, Douglas. 1984. Financial intermediation and delegated monitoring. Review of Economic Studies 51, 393-414.

Elyasiani, Elyas, Kenneth Kopecky, and David VanHoose. 1995. Costs of adjustment, portfolio separation, and the dynamic behavior of bank loans and deposits. Journal of Money, Credit and Banking, 27, 955-974.

Federal Deposit Insurance Corporation, 2010, Incorporating employee compensation criteria into the risk assessment system, Advance Notice of Proposed Rulemaking 12 CFR Part 327, January 12.

Grant, C. Terry, and Gerry Grant, 2008, Can regulations curb excessive executive pay? Strategic Finance, September, 31-39.

Hill, Jennifer, 2009, New trends in the regulation of executive remuneration, Working Paper 10-05, Vanderbilt Law School.

Kopecky, Kenneth, and David VanHoose, 2010, Can Capital Requirements Induce Private Monitoring That Is Socially Optimal? Working Paper, Temple University and Baylor University.

Kopecky, Kenneth, and David VanHoose, 2006. Capital regulation, heterogeneous monitoring costs, and aggregate loan quality. Journal of Banking and Finance $30,2235-2255$.

Kose, John, Anthony Saunders, and Lemma Senbet, 2000, A theory of bank regulation and management compensation, Review of Financial Studies 13, 95-125.

Macey, Jonathan, and Maureen O'Hara, 2003, The corporate governance of banks, Federal Reserve Bank of New York Economic Policy Review 16, 91-107. Mason, David, 2009, Why government control of bank salaries will hurt, not help, the 
economy, Backgrounder, Heritage Foundation, No. 2336, November 4.

Raviv, Alon, and Yoram Landskroner, 2009, The 2007-2009 financial crisis and executive compensation: Analysis and a proposal for a novel structure, Working Paper, New York University, June 15.

VanHoose, David, 2011, Regulation of bank management compensation, in Financial Market Regulation: Legislation and Implications, ed. John Tatom, Springer, 163183 